\title{
VARIAÇÃO TEMPORAL DAS CHUVAS NO NORTE DE MINAS GERAIS: EIXO ARINOS, JANUÁRIA E SALINAS
}

\author{
Felipe Pereira de Moura ${ }^{(a)}$; Carlos Henrique Jardim ${ }^{(b)}$ \\ (a) Graduando, Depto. Geografia/IGC, UFMG, felipegeografia@ hotmail.com \\ (b) Prof. Adjunto, Depto. Geografia/IGC, UFMG, dxhenrique@gmail.com
}

\section{Eixo: Climatologia em Diferentes Níveis Escalares: Mudanças e Variabilidades}

\begin{abstract}
Resumo
Este trabalho busca analisar as características da variabilidade das chuvas no norte de Minas Gerais com base nas séries históricas das estações meteorológicas do INMET instaladas nos municípios de Arinos, Januária e Salinas, considerando os totais anuais de chuva, os desvios e valores de tendência e correlações. Os resultados mostraram a influência do relevo e atuação dos sistemas atmosféricos na diferenciação das características climáticas da área de estudo.
\end{abstract}

Palavras chave: Chuvas, variabilidade, relevo.

\section{Introdução}

O clima pode ser considerado um dos mais importantes componentes da natureza, na medida em que afeta diversos processos naturais, como os geomorfológicos, pedológicos e biológicos, além de sua influência sobre as sociedades humanas e suas formas de organização (AYOADE, 1991). É fundamental sua compreensão como um sistema natural complexo, aberto, dinâmico, adaptativo e auto-regulável (MONTEIRO, 1975), possibilitando através de uma visão sistêmica entender como uma característica do clima, enquanto sistema natural, a interdependência das partes que se constituem como um conjunto (DREW, 1989).

A chuva se caracteriza como um elemento fundamental da dinâmica climática, uma vez que sua distribuição no tempo e no espaço traz impactos diretos sobre as organizações sociais e as atividades do homem. Logo, torna-se essencial a compreensão dos aspectos relacionados a chuvas, dentre os quais possui significativa importância a distribuição das chuvas e a variabilidade, esta entendida como a variação dos valores de precipitação dentro de um período em uma série temporal. Diversos fatores influenciam a distribuição da precipitação sobre o espaço, como, por exemplo, o relevo, a distância relativa aos grandes corpos hídricos, características e direção das massas de ar que predominam em determinada área etc. (AYOADE, 1991). 


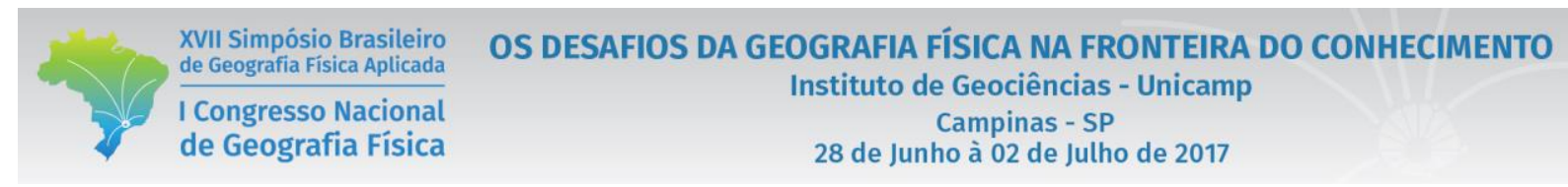

A distância em relação aos grandes corpos hídricos afeta a quantidade de umidade disponível naquele ambiente, enquanto que o relevo pode servir como barreira orográfica para o avanço de massas de ar e outros sistemas ou influenciar outros elementos climáticos. O relevo se caracteriza como um dos fatores influentes sobre a organização do clima, com efeitos que vão desde níveis zonais aos topoclimas e microclimas. A altitude, enquanto um aspecto do relevo pode afetar também a temperatura do ar em nível local (FROTA e SCHIFFER, 2006). Logo, a conformação do relevo se estabelece como fator que condiciona e modifica o clima, na medida em que seus aspectos, como a altitude, orientação das vertentes e a situação topográfica influenciam no comportamento diário e horário dos parâmetros climáticos (AYOADE, 1991).

Este artigo apresenta como objetivo principal analisar a dinâmica de variação dos elementos climáticos a partir da gênese e variação temporal das chuvas, considerando os dados das séries históricas das estações meteorológicas do INMET dos municípios de Arinos, Januária e Salinas, em Minas Gerais. Essa análise tem como finalidade verificar possíveis padrões, variações e tendências nos dados de climáticos.

\section{Localização da Área de Estudo}

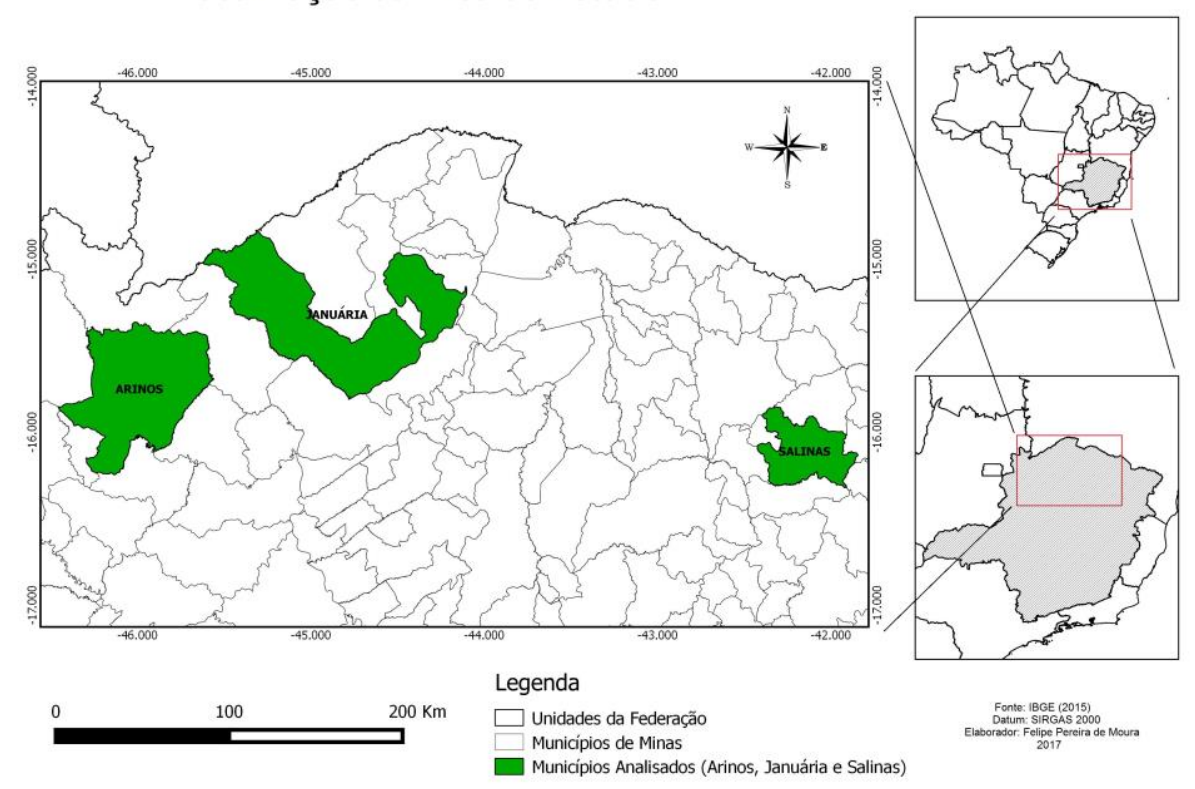

Figura 1 - Localizaçao da área de estudo. Fonte: IBGE, 2015. Elaboração: Felipe Pereira de Moura

A área de estudo compreende municípios situados ao norte do estado de Minas Gerais, sendo eles Arinos, Januária e Salinas, estabelecendo um eixo Oeste - Leste, permitindo, desta forma, estabelecer relações entre os níveis de precipitação identificados em cada município e sua relação com fatores geográficos de superfície, com destaque para a conformação do relevo e da distância em relação aos oceanos. 
Este resumo está ligado a um projeto em desenvolvimento (Projeto APQ-03773-14 Sustentabilidade da bacia do Rio Pandeiros-MG) que é financiado pela Fundação de Amparo à Pesquisa do Estado de Minas Gerais (FAPEMIG), apresentando alguns resultados parciais. O projeto tem como objetivo compreender e caracterizar a dinâmica das chuvas na região de Januária, no norte do estado de Minas Gerais, de modo a considerar sua relação com a dinâmica atmosférica e fatores locais de superfície.

\section{Materiais e Métodos}

Os dados pluviométricos analisados foram mensurados por estações meteorológicas convencionais de superfície do Instituto Nacional de Meteorologia (INMET) e disponibilizados através do Banco de Dados Meteorológicos para Ensino e Pesquisa (BDMEP) no site (www.inmet.gov.br). As séries históricas utilizadas compreendem o período de 01/01/1964 a 31/12/2016. As estações meteorológicas selecionadas estão localizadas nos municípios de Arinos, Januária e Salinas, em Minas Gerais (tabela I).

Tabela I - Estações utilizadas na pesquisa e suas respectivas latitude, longitude e altitude.

\begin{tabular}{|l|l|l|l|}
\hline \multicolumn{1}{|c|}{ Estações } & \multicolumn{1}{c|}{ Latitude } & \multicolumn{1}{c|}{ Longitude } & \multicolumn{1}{c|}{ Altitude (metros) } \\
\hline Arinos & $-15,899894$ & $-46,050039$ & 519 \\
\hline Januária & $-15,448446$ & $-44,36008$ & 473,71 \\
\hline Salinas & $-16,15995$ & $-42,300042$ & 471,32 \\
\hline
\end{tabular}

Fonte: BDMEP/INMET. Elaboração: Felipe Pereira de Moura

Os dados foram tabulados e trabalhados através de procedimentos estatísticos específicos, através do uso do software Microsoft Excel versão 2010. Foi obtido para as estações selecionadas um conjunto de valores e gráficos relativos à precipitação mensal e o acumulado anual, além dos desvios em relação às médias. Também foram analisados os dados das Normais Climatológicas 1961-1990 (DNMET, 1992).

A consistência dos dados foi analisada de modo que falhas presentes nas séries temporais fossem devidamente trabalhadas. Os anos que apresentaram falhas em mais de dois meses foram desconsiderados de modo a evitar grandes distorções na análise. Para os anos que apresentaram até dois meses de falhas, estas foram corrigidas através do uso da média aritmética simples, baseada no conjunto de meses iguais que não apresentaram falhas.

Dentre as técnicas utilizadas neste trabalho, destaca-se a análise de regressão linear simples, que busca estabelecer a relação ou tendência de variação entre os elementos climáticos em função do tempo. Tembém se destaca as sobreposições realizadas através dos gráficos, dos dados de precipitação (totais anuais e desvios percentuais) com os períodos de ocorrência de eventos de El Ninõ e La Ninã e com a Oscilação Decadal do Pacífico (ODP). 


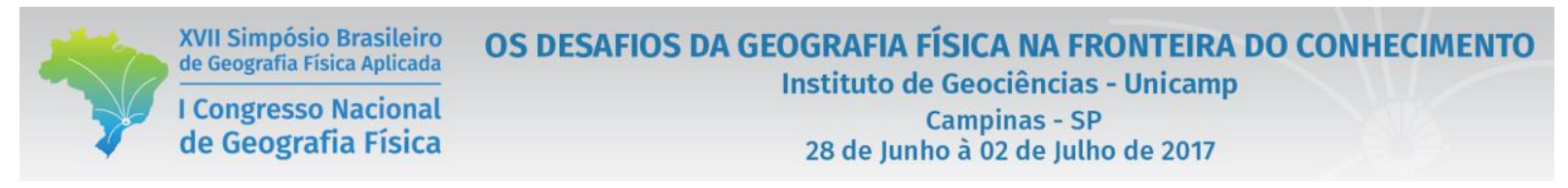

\section{Resultados}

Conforme os dados das normais climatológicas para o período de 1961 - 1990 disponibilizados pelo Departamento Nacional de Meteorologia (1992), a precipitação anual média é de 1275,2 mm em Arinos, 826,5 mm em Januária e 846,1 mm em Salinas. Nota-se pela análise das normais climatológicas e também dos valores do acumulado anual de precipitação presentes nos gráficos da figura 2 que o município de Arinos possui diferença significativa em comparação à Januária e Salinas.
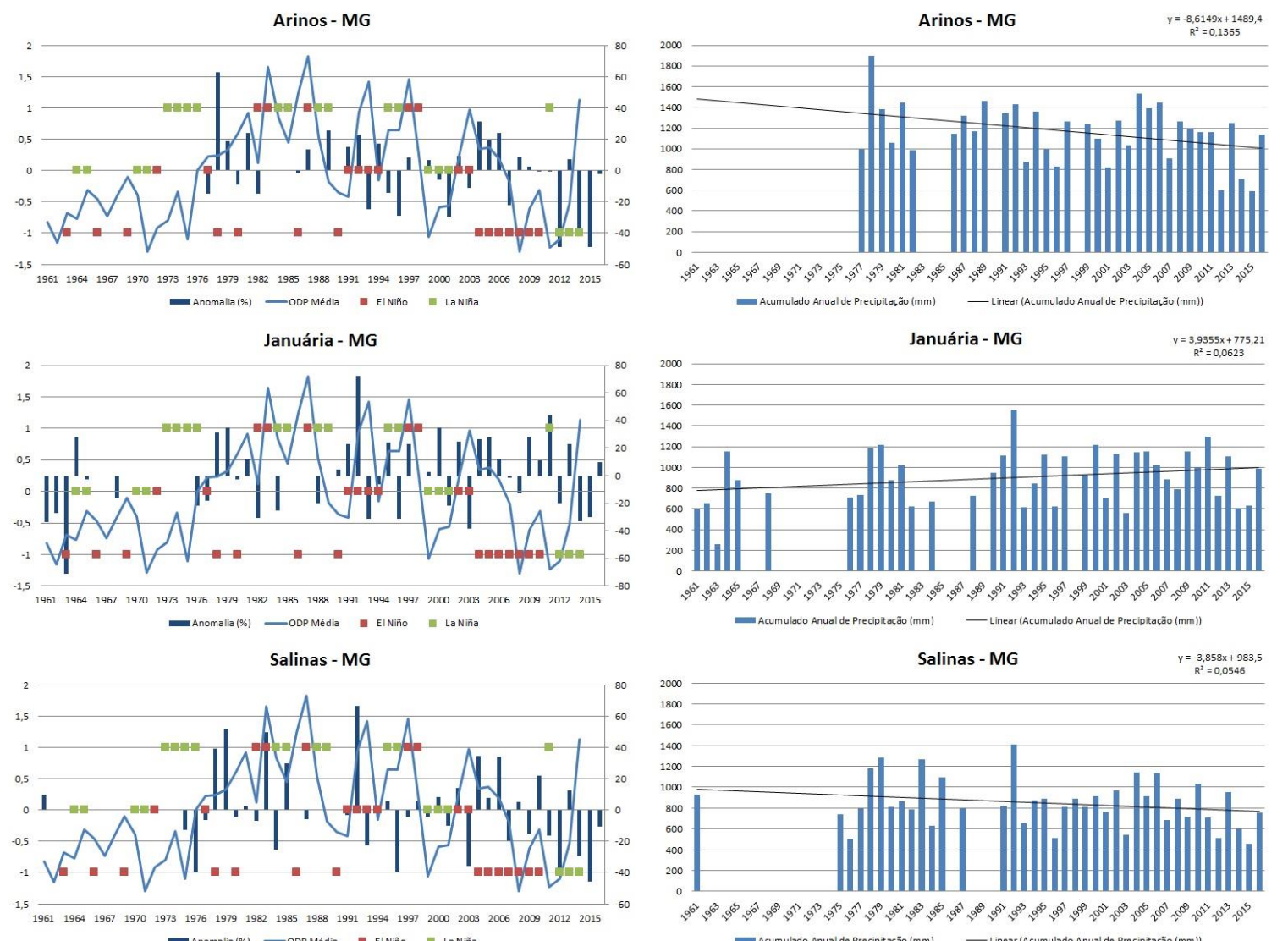

Figura 2 - Gráficos à esquerda: Desvios (\%) dos totais de chuva (eixo esquerdo) e relação com ODP, El Niño e La Niña (eixo da direita). El Niño/La Niña: forte (+1); moderado (0); fraco (-1). Gráficos à direita: Acumulado Anual de Precipitação e regressão linear. Elaboração: Carlos H. Jardim/Felipe Pereira de Moura.

A dimensão espacial, no que se refere à proximidade com grandes corpos hídricos, não parece exercer influência, uma vez que Arinos é o município mais a oeste dentre aqueles analisados, apresentando o maior valor dos totais de chuva. Já Salinas, que está mais a leste e, portanto, mais próximo ao oceano, apresenta totais similares ao município de Januária. 
A explicação para a diferença nos totais entre esses municípios se encontra na influência tanto do relevo, quanto de aspectos dinâmicos ligados à circulação das massas de ar. Mesmo fazendo parte da mesorregião Norte de Minas, Salinas está situada na bacia hidrográfica do Jequitinhonha, apresentando características climáticas similares aos dos municípios semiáridos do vale do Jequitinhonha, conforme pode se verificar no Diagnóstico Ambiental da Bacia do Rio Jequitinhonha, realizado pelo IBGE (1997). Nessa porção nordeste do território da região sudeste do Brasil, verifica-se baixa frequência de atuação das descontinuidades polares de SW, gerando dependência das chuvas causadas pela atuação de linhas de instabilidade (NIMER, 1989).

A análise da regressão linear para as três estações não apresentou nenhum indicativo de correlação entre o volume de precipitação e sua progressão no tempo, impossibilitando especular sobre qualquer tendência de aumento ou diminuição dos níveis de precipitação em função do tempo.

\section{Considerações Finais}

A análise dos dados permitiu verificar a complexidade presente na dinâmica climática, uma vez que resulta das interações estabelecidas entre a dinâmica atmosférica e fatores locais de superfície. Aspectos como a proxímidade a grandes corpos hídricos não foram determinantes no entendimento das características climáticas das áreas analisadas, enquanto que o relevo e a atuação de sistemas atmosféricos tiveram maior destaque, demonstrando a importância de se analisar diversos fatores para a compreensão adequada do clima.

\section{Bibliografia}

AYOADE. J. O. Introdução à climatologia para os trópicos. $3^{\text {a }}$ ed. Rio de Janeiro: Ed. Bertrand, 1991.

DNMET. Departamento Nacional de Meteorologia. Normais Climatológicas (1961- 1990). Brasília-DF, 1992.

DREW, D. Processos interativos: homem-meio ambiente. $2^{\text {a }}$ ed. Rio de Janeiro, Bertrand Brasil, 1989.

FROTA, A. B.; SCHIFFER, S. Manual de Conforto Térmico. 7ª ed. São Paulo: Ed. Studio Nobel, 2006.

IBGE - Instituto Brasileiro de Geografia e Estatística. Diagnóstico Ambiental da Bacia do Rio Jequitinhonha, 1997. Disponível em: <http://www.ibge.gov.br/home/geociencias/recursosnaturais/diagnosticos_levantamentos/> Acesso em: 07 jan. 2017.

MONTEIRO, C. A. F. Teoria e clima urbano. Tese de Livre-Docência - Faculdade de Filosofia, Letras e Ciências Humanas, Universidade de São Paulo, São Paulo, 1975.

NIMER, E. Climatologia do Brasil. 2.ed. Rio de Janeiro: IBGE, 1989. 